\title{
Caring Teaching as a Moral Practice: An Exploratory Study on Perceived Dimensions of Caring Teaching
}

\author{
Khalil Gholami $^{1,2}$ and Kirsi Tirri ${ }^{2}$ \\ ${ }^{1}$ Department of Education, University of Kurdistan, P.O. Box 416, Sanandaj 15177-66177, Iran \\ ${ }^{2}$ Department of Teacher Education, University of Helsinki, P.O. Box 9 (Siltavuorenpenger 5), 00014 Helsinki, Finland
}

Correspondence should be addressed to Khalil Gholami, khalil.gholami@helsinki.fi

Received 21 February 2012; Revised 11 June 2012; Accepted 12 June 2012

Academic Editor: Terence J. Lovat

Copyright ( $\odot 2012 \mathrm{~K}$. Gholami and K. Tirri. This is an open access article distributed under the Creative Commons Attribution License, which permits unrestricted use, distribution, and reproduction in any medium, provided the original work is properly cited.

\begin{abstract}
Caring teaching is a conceptual framework used to gain an insight into the moral aspect of teaching. Using a quantitative research approach, we studied 556 teachers in order to explore their perceived dimensions of caring teaching. Drawing on existing literature, we found that caring teaching has been elaborated in line with two broad concepts: personal care and academic care. Considering these concepts, we developed the Caring Teaching Scale with which we identified four dimensions of caring teaching: the nurturing of a student's character, didactical bias, awareness, and respectful didactics. A meta-analysis reflection suggests that the nurturing of students' characters and awareness represent personal care while didactical bias and respectful didactics call for academic care. Further analysis showed that these teachers attached more pedagogical value to personal care. Controlling for two demographic variables, we found statistically significant differences with regard to gender and caring teaching.
\end{abstract}

\section{Introduction}

The moral aspects of human life have faced formidable challenges because of the emergence of new value systems rooted in the increasing individualization of modern Western societies [1]. Educational agencies such as schools and teachers are affected by this trend and need to consider it in their daily activities. Sockett and LePage (2002) argue that moral language is missing from the classroom [2]. As such "schools can no longer afford to focus solely on delivering the academic curricula; they are also responsible for establishing and maintaining schools' cultures that empower students and teachers alike to negotiate the diverse values and social norms of their communities" [3]. This raises the question, how should schools and teachers deal with the moral elements of their responsibilities? In line with this, numerous studies have dealt with exploring one or more elements of the ethical or moral nature of teaching [4-8]. These studies show that teaching is a moral activity by nature, and thus teachers are responsible for improving moral life in the classroom. According to Fenstermacher, "what makes teaching a moral endeavor is that it is, quite centrally, human action undertaken in regard to human beings. Thus matters of what is fair, right, just, and virtuous are always present.... The teacher's conduct at all times and in all ways, is a moral matter" [9]. This understanding raises two important questions regarding the moral aspect of teaching: what are the ends of teaching as a moral activity? And, in addition, how can these ends be realized through the practice of teaching?

Regarding the first question, most researchers highlight the idea that the mission of teaching, as a moral activity, is to develop the moral character and virtues of the students. Hansen (1998) states that many classroom teachers place moral considerations at the heart of their activities. These teachers "see themselves as more skilled technicians or knowledge conveyers.... These teachers feel that there are extraordinary possibilities in their role to be a force for good: to help young people to broaden their intellectual and moral horizons and to deepen their connection to their own intellectual and human capacities" [6]. The rationality behind this perspective is to emphasize that nurturing the whole character of one's students takes precedence over their academic properties $[10,11]$. 
Considering the idea that teaching as a moral activity aims at developing the moral character and virtues of students, the next concern is how virtues can be dealt with in the classroom. The question, "Can virtues be taught?" is perhaps the oldest in moral philosophy [5]. One of the main arguments in the existing literature suggests that "Moral virtues cannot be taught" $[6,12-14]$. Fenstermacher states that "from Plato's Meno to Ryle's The Concept of Mind, it has been generally accepted that in Anglo-American philosophy virtue cannot be taught.... Virtue is not conveyed in the way academic content is conveyed, rather it is acquired or picked up by association with people who are themselves virtuous. . . thus teachers must themselves be virtuous persons if they are to foster virtues in their students" [14]. In relation to the argument that virtues cannot be taught, the question that arises is how can teachers develop students' moral and intellectual lives?

Caring practice is widely believed to be a vital approach in dealing with the moral component of teaching [15-18]. It is a new and different approach to teaching practice since teachers consider different ends, and their own pedagogical orientation in their personal philosophy of teaching. The "principal end" of teachers, in caring teaching, is to nurture the whole character and dignity of the students $[10,11,19]$, whilst in other teaching approaches, such as "effective teaching," the dominant duty of teachers is to transmit educational materials to students. In caring teaching, however, this end is overridden by virtues embedded in the main ends of the teachers. In addition, in the caring teaching approach, teachers' pedagogical orientations are more "moral and emotional" than technical and methodological. In other words, teachers prefer to establish a kind of learning environment, in which humor, fun, enjoyment, fairness, trust, friendship, and respect for students are considered to be at the core of the teachers' practice. Such an environment, in turn, encourages and prepares students to be effectively engaged in learning activities.

Caring teaching, accordingly, can be reflected in teachers' activities in two integrated and interrelated ways, elaborating the moral aspects of young people. In the first place, teachers help students enhance their moral competency by nurturing the character of the students. In addition to academic skills, teachers here care about students' basic social and personal skills for life outside the school community $[10,16]$. In the second place, teachers should have good manner and integrate it into their pedagogical decisions. Fenstermacher has stated that when teachers are characterized by traits such as honesty, compassion, truthfulness, fairness, courage, moderation, and generosity in their daily activities, their students will pick up these virtues in their interaction with teachers [14].

Caring teaching has been widely studied using qualitative research approach. In our previous work [10], we elaborated the nature of caring teaching in relation with teachers' practical knowledge. Drawing on our previous works, we have developed a framework to gain further insights into the dimensions of caring teaching. Since there is a lack of significant quantitative research on caring teaching, we have developed a questionnaire based on our previous framework in order to gain deeper insights into the topic in a larger population. We believe that, like many other human traits, it will be an essential research effort to measure the characteristics of caring teachers in different contexts with a large population.

\section{Theoretical Framework for Studying Caring Teaching Dimensions}

In order to develop a conceptual framework with regard to caring teaching and thus identify its dimensions, we relied on findings from our own previous qualitative research and the existing literature on caring teaching. Drawing on Valli, Hansen (1998) explains three approaches to the moral foundation of teaching: the deliberative, the relational, and the critical. The deliberative viewpoint supports teachers to reflect on the purposes of their activities and justify it based on moral and rational principles rooted and constrained by the community's consensus. In the relational approach, the empathic understanding in the relationship between the carer and the cared-for is more important than abstract principles. In the critical approach, teachers are morally responsible for helping students to deconstruct the dominant value system and ideology [6].

In this study, we mainly base our work on the relational approach in order to explore the possible dimensions of caring teaching. According to this approach, "a true caring relationship depends on a teacher's ability to identify and meet students' needs and is affirmed by students' confirmation of that caring" [15]. Caring, as a relational phenomenon, demands that the teacher knows his/her students well in order to respond to their needs, desires, and struggles [20]. It is also concerned with the teachers' sensitivity to students' feelings, academic development, and their dignity. According to Nodding, a caring relationship "requires engrossment and motivational displacement" whereby teachers replace their own needs and desires with the needs and desires of their students $[15,19]$. Reviewing the existing literature on relational caring teaching suggests that the behaviors and characteristics of caring teachers can be conceptualized into two main categories, each aiming at different but interrelated intentions: personal care and academic care. The common features of these dimensions are to put sensitivity, respectfulness, and "commitment" at the heart of teachers' pedagogical decisions.

2.1. Personal Care. Personal care emphasizes the overall growth of a student as a "person" $[16,18,21]$. In personal care, teachers act like mothers to nurture the whole character of the students. Rosiek (2003) states that teachers should deal with students as whole human beings and need to respond them as emotional, moral, social, cultural, and cognitive beings [22]. Empirical studies show that teachers are expected to meet such an important task in terms of two different professional obligations: responsibility for improving the social, emotional, intellectual, and moral features of students and being sensitive to deal with their personal and interpersonal problems [10, 23, 24]. Regarding the first obligation, Nias (1999) suggests that caring teaching involves care as affectivity, as responsibility for the learner, as 
responsibility for relationships in school, and as professional identify for teachers [25]. In addition, caring teachers are expected to listen, understand, and take care of students' personal and interpersonal problems inside and outside school and deal with these problems with empathy and patience $[10,15]$. In an empirical study, $38.46 \%$ of female students and $45 \%$ of male students thought that their teachers should be involved in interpersonal relationship with students in different ways [24]. In general, the main intention in personal care is to help students develop their identity and dignity as human beings in order to become good citizens, establishing a productive and moral relationship with society.

2.2. Academic Care. Academic care involves teachers' pedagogical activities that deal with learning activities, classroom management, and the rules and regulations that teachers use for enriching the learning environment. In academic care, teachers are still sensitive to the possible harmful emotional consequences of their practice [10]. In other words, teachers are limited in the means by which they bring about learning. de Guzman et al. found that caring teachers were perceived as achievement, task, goal, and change orientated where they are expected to help students improve their learning and achievement [20]. In another study, $45 \%$ of the female and $18 \%$ of the male students thought that caring teachers' behavior associated with academic care, fairness, and providing equal opportunities for all students to engage in academic activities was important element in academic care [10,24]. In such cases, being fair towards students created good feelings and emotions in them. In general, academic care has two sides in terms of caring teachers' behavior. One is to establish an enriched and productive learning environment where everybody's needs and capabilities are met by the teachers' pedagogical activities. On the other hand, teachers' actions should be sensitive to the emotional reactions of the students.

\section{Purpose of the Paper}

The main aim of this paper is to explore and describe the basic components of teachers' perceived caring practice in order to gain insights into the moral aspect of teaching. Relying on previous qualitative empirical research and theoretical frameworks, we developed a questionnaire and asked primary, secondary, and high-school teachers in Kurdistan (Iran) to respond to it in order to capture their perceived caring teaching characteristics. The second aim of the paper is to describe and analyze caring teaching characteristics in the target population. In this way, we will examine the level of caring teaching in the data in general and in regard to demographic variables, gender, and the subject matters taught by the teachers.

\section{Methods}

4.1. Design. One of the main concerns in educational research is to ensure that the knowledge claim of research is consistent with its methodological operations. In other words, how appropriate are the research methods for examining the knowledge that the research claims to produce. Caring teaching is a complex area, and it should be studied with different methods, particularly a mixed method approach. In line with this, in our previous works, we elaborated on caring teaching based on findings from qualitative research [10]. In this paper, we will continue our reflections on caring teaching using a quantitative approach. Thus, the tools (e.g., our questionnaire), concepts, and research framework and procedure, in this paper, rely on previous empirical qualitative studies. The questionnaire, as an important tool, was essentially developed out of the interviews we had with the teachers in the qualitative phase of our research (see Section 4.3). Therefore, this paper draws on findings from a research project that has used a mixed approach, but, here, we primarily present the results of the quantitative stage.

4.2. Participants. A total of 600 primary, middle, and highschool teachers (for more information on Iran's teacher education system, refer to the other paper by Gholami and Tirri in this volume) were asked to participate in our study on a voluntary base, and we used nonprobability sampling. The teachers were teaching in province of Kurdistan, in Iran. Kurdistan is one of the provinces in Iran with a minority Kurdish ethnic background. The questionnaires were personally delivered to the school administration to distribute among teachers. After returning the questionnaires, we found that some 44 cases had significant missing data, and these were excluded from our data analysis. So 556 cases were selected and entered into Statistical Package for Social Science (SPSS) for analysis. Table 1 illustrates the sample description.

4.3. Data Collection Tool. Drawing on existing literature and our previous studies, we developed a questionnaire in order to measure caring teaching: the Caring Teaching Scale (CTS). In line with the concept of caring teaching, we first provided a pool of items. Items were mainly extracted from the content of our interviews with teachers in the previous studies. The initial draft consisted of 30 items representing academic care and personal care. These items were then sent to 20 teachers in order to check the contents relevance and wording. Unclear items were reworded, and four items were removed from the list in response to the feedback from the teachers. At this stage, the instrument for administration consisted of 26 items, each concept (personal and academic care) 13 items, on a 5-point Likert Scale, where strongly agree $=5$, agree $=4$, neither $=3$, disagree $=2$, and strongly disagree $=1$. We should point out that the concepts of personal care and academic care were not statistical dimensions of caring teaching but simply a conceptual framework in order to explore the possible dimensions of caring teaching.

4.4. Data Analysis. Exploratory Factor Analysis with Principle Component Analysis, Direct Oblimin was conducted in order to extract the basic dimensions or subscales of the Caring Teaching Scale. The results yielded six components with eigenvalues greater than one, explaining the total variance of 55.25 for the solution. KMO (0.88) and Bartlett's test $\left(\mathrm{df}=325 ; x^{2}=4476.90 ; \operatorname{sig}=.000\right)$ confirmed that we could proceed with the factor analysis. In this stage, however, the determinant was.000, and thus we conducted a further 
TABle 1: Sample description.

\begin{tabular}{|c|c|c|c|c|}
\hline & $\begin{array}{l}\text { Primary teachers } \\
\qquad(N=125)\end{array}$ & $\begin{array}{l}\text { Middle school teachers } \\
\qquad(N=221)\end{array}$ & $\begin{array}{l}\text { High-school teachers } \\
\qquad(N=204)\end{array}$ & $\begin{array}{c}\text { Total } \\
(N=556)\end{array}$ \\
\hline \multicolumn{5}{|l|}{ Gender $N(\%)$} \\
\hline Female & $40(32.0)$ & $96(43.4)$ & $88(43.1)$ & $224(40.3)$ \\
\hline Male & $85(68.0)$ & $125(56.6)$ & $116(56.9)$ & $332(59.7)$ \\
\hline \multicolumn{5}{|l|}{ Age } \\
\hline Mean & 35.65 & 34.64 & 35.27 & 35.08 \\
\hline (Min-Max) & $(21-50)$ & $(20-52)$ & $(20-50)$ & $(20-52)$ \\
\hline SD & 6.55 & 6.92 & 5.58 & 6.35 \\
\hline \multicolumn{5}{|l|}{ Experience } \\
\hline Mean & 14.45 & 13.24 & 13.61 & 13.63 \\
\hline (Min-Max) & $(1-23)$ & $(1-28)$ & $(1-27)$ & $(1-28)$ \\
\hline SD & 6.68 & 7.15 & 6.02 & 6.63 \\
\hline
\end{tabular}

TABLE 2: The comparison of random eigenvalues (PA) and real eigenvalues for factor retention.

\begin{tabular}{lcc}
\hline Factors & Random eigenvalues & Real eigenvalues \\
\hline 1 & 1.41 & 6.28 \\
2 & 1.35 & 2.34 \\
3 & 1.30 & 1.63 \\
4 & 1.26 & 1.28 \\
5 & 1.22 & 0.98 \\
6 & 1.19 & 0.84 \\
\hline
\end{tabular}

investigation to modify the model. Studying the communalities, we found that four items had low communalities (i.e., lower than 0.25). When we removed these items from the analysis, it resulted in a better solution with a determinant $=$ 0.001. Thus, we proceeded with the new factor analysis to extract the main dimension of caring teaching.

The new solution (after deleting the four items with the lowest communalities) resulted in four factors with eigenvalues greater than 1 . A Kaiser Criterion $(\mathrm{k} 1)$, which retains factors with eigenvalues greater than 1 , is argued for, as finite samples would tend to overestimate the number of factors $[26,27]$. Accordingly, we decided to use parallel analysis (PA) to make sure that an appropriate number of factors were retained. PA "involves the construction of a number of correlation matrices of random variables based on the same sample size and the number of variables in the real data set. The average eigenvalues from the random correlation matrices are then compared to the eigenvalues from the real data correlation matrix. Factors corresponding to the actual eigenvalues that are greater than the parallel average random eigenvalues should be retained" [27]. Using parallel analysis, we created a set of random data with 100 times replicated. The result of the parallel analysis is compared to the results from the actual data set in Table 2 .

According to Table 2, we decided to retain four factors that yielded real eigenvalues greater than the random eigenvalues. At this stage, a new Principle Component Analysis with a 4-fixed factor solution and Direct Oblimin rotation was conducted and considered the basis for reporting our results. The results showed that out of 22 items, 7 items loaded on factor 1, 3 items on factor 2, 4 items on factor 3, and 6 items on factor 4; one item did not have enough loading value on these factors and was thus deleted from the analysis.

Table 3 shows the factor-loading values and communalities $\left(h^{2}\right)$ of items in the final factor analysis. Therefore, the final instrument for analysis consisted of 21 items, from which 10 items were reversed and thus recoded during the data analysis and description (see the Appendix for more information about items). In this way, a higher score on the scale indicates more caring in teaching.

\section{Results}

5.1. What Are the Dimensions of Caring Teaching? The results of the factor analysis showed that the teachers perceived four dimensions with regard to caring teaching, with factor 1 explaining 28.58 variance, factor $2,10.66$, factor 3, 7.44, factor $4,5.84$, and a total variance of 52.54 for the whole scale. Table 4 shows the Cronbach's Alpha coefficients of these dimensions. As presented, the Alpha coefficients for the four dimensions range from $\alpha=0.69$ to $\alpha=0.85$ and thus show a satisfactory degree of reliability.

Considering the wording and meaning of the items corresponding to each factor and drawing on our previous qualitative research $[10,23]$ and in line with personal and academic care, we named four dimensions of caring teaching: factor 1 nurture students' character, factor 2 didactical bias, factor 3 awareness, and factor 4 respectful didactics. A meta-analysis suggested that nurture students' character and awareness deal with personal care and didactical bias and respectful didactics deal with academic care. In order to gain more insight into these dimensions, see Table 6 with final items included in the CTS.

"Nurture students' character" triggers teachers' pedagogical decisions that aim at cultivating the student's character as a human being. These activities are meant to improve students' social, moral, emotional, and intellectual capabilities in order to become good and productive citizens in their society. "Awareness" concerns teachers' involvement in 
TABLE 3: Factor loading and communalities $\left(h^{2}\right)$ of the caring teaching scale.

\begin{tabular}{|c|c|c|c|c|c|c|c|}
\hline Items & Factor 1 & Factor 2 & Factor 3 & Factor 4 & $h^{2}$ & Mean & $\mathrm{SD}$ \\
\hline 1 & 0.80 & & & & 0.62 & 4.06 & 1.15 \\
\hline 2 & 0.799 & & & & 0.69 & 4.22 & 1.07 \\
\hline 3 & 0.793 & & & & 0.62 & 3.96 & 0.90 \\
\hline 4 & 0.78 & & & & 0.64 & 4.15 & 0.81 \\
\hline 5 & 0.66 & & & & 0.59 & 3.96 & 0.95 \\
\hline 6 & 0.57 & & & & 0.33 & 3.52 & 1.02 \\
\hline 7 & 0.43 & & & & 0.33 & 3.74 & 1.02 \\
\hline 8 & & 0.86 & & & 0.70 & 3.56 & 1.07 \\
\hline 9 & & 0.84 & & & 0.74 & 3.56 & 1.15 \\
\hline 10 & & 0.75 & & & 0.61 & 3.31 & 1.18 \\
\hline 11 & & & 0.76 & & 0.58 & 4.54 & 0.66 \\
\hline 12 & & & 0.70 & & 0.57 & 4.40 & 0.82 \\
\hline 13 & & & 0.64 & & 0.53 & 4.42 & 0.80 \\
\hline 14 & & & 0.60 & & 0.39 & 4.24 & 0.75 \\
\hline 15 & & & & 0.73 & 0.49 & 3.56 & 1.11 \\
\hline 16 & & & & 0.71 & 0.51 & 3.42 & 1.08 \\
\hline 17 & & & & 0.70 & 0.58 & 3.98 & 0.98 \\
\hline 18 & & & & 0.63 & 0.48 & 3.98 & 1.02 \\
\hline 19 & & & & 0.62 & 0.48 & 3.80 & 1.00 \\
\hline 20 & & & & 0.52 & 0.31 & 3.31 & 1.05 \\
\hline 21 & & & & 0.44 & 0.32 & 3.39 & 1.01 \\
\hline
\end{tabular}

TABLE 4: Four dimensions of caring teaching.

\begin{tabular}{|c|c|c|c|c|}
\hline Dimensions & Items & Alpha $\alpha$ & Mean & $\mathrm{SD}$ \\
\hline Nurture students' character & $1,2,3,4,5,6,7$ & 0.85 & 3.94 & 0.68 \\
\hline Didactical bias & $8,9,10$ & 0.77 & 2.52 & 0.93 \\
\hline Awareness & $11,12,13,14$ & 0.69 & 4.40 & 0.54 \\
\hline Respectful didactics & $15,16,17,18,19,20,21$ & 0.78 & 3.63 & 0.68 \\
\hline Caring teaching scale & & 0.83 & 3.72 & 0.48 \\
\hline
\end{tabular}

knowing students' personal problems, needs, and capabilities. This is a basic dimension of caring teaching, with which teachers may help students nurture their character as well as their academic properties. "Didactical bias" involves teachers' activities that avoid any "bias" towards particular students, for example, giving them more chances or constraining their academic opportunities. Accordingly, teachers should provide equal opportunities for all students to be engaged in learning activities regardless of their academic status and personal capabilities. "Respectful didactics," which mainly aims at bringing about learning, should still respect students and avoid violating their dignity as human beings.

5.2. Description and Analysis of Caring Teaching. The second purpose of this paper is to present a description and analysis of the caring teaching dimensions as explored in the present research. Considering the four dimensions, the results showed that teachers perceived awareness $(M=4.40$; $\mathrm{SD}=0.54$ ) as the most important dimension of caring teachers; didactical bias however received the lowest score
$(M=2.52 ; \mathrm{SD}=0.93)$. The results for the other dimensions and for the whole Caring Teaching Scale are presented in Table 4. As we mentioned, "respectful didactics" and "didactical bias" represent the concept of academic care, while "nurture students' character" and "awareness" account for personal care. In order to gain a clear insight into the role of both personal and academic care in caring teaching, we combined the scores of their corresponding dimensions and studied the difference between them and the score for the whole scale (i.e., the mean score of four dimensions). The results showed that personal care $(M=4.17, \mathrm{SD}=0.45)$ received a higher score and academic care $(M=3.08, \mathrm{SD}=$ 0.62 ) received a lower score than the mean score of the Caring Teaching Scale $(M=3.72, \mathrm{SD}=0.48)$. The details are presented in Table 5 .

Considering the demographic variables, we further studied the effects of gender and subject matter on both personal and academic care. A multivariate test on the relationship between gender and both personal and academic care showed statistically significant results, indicating a 


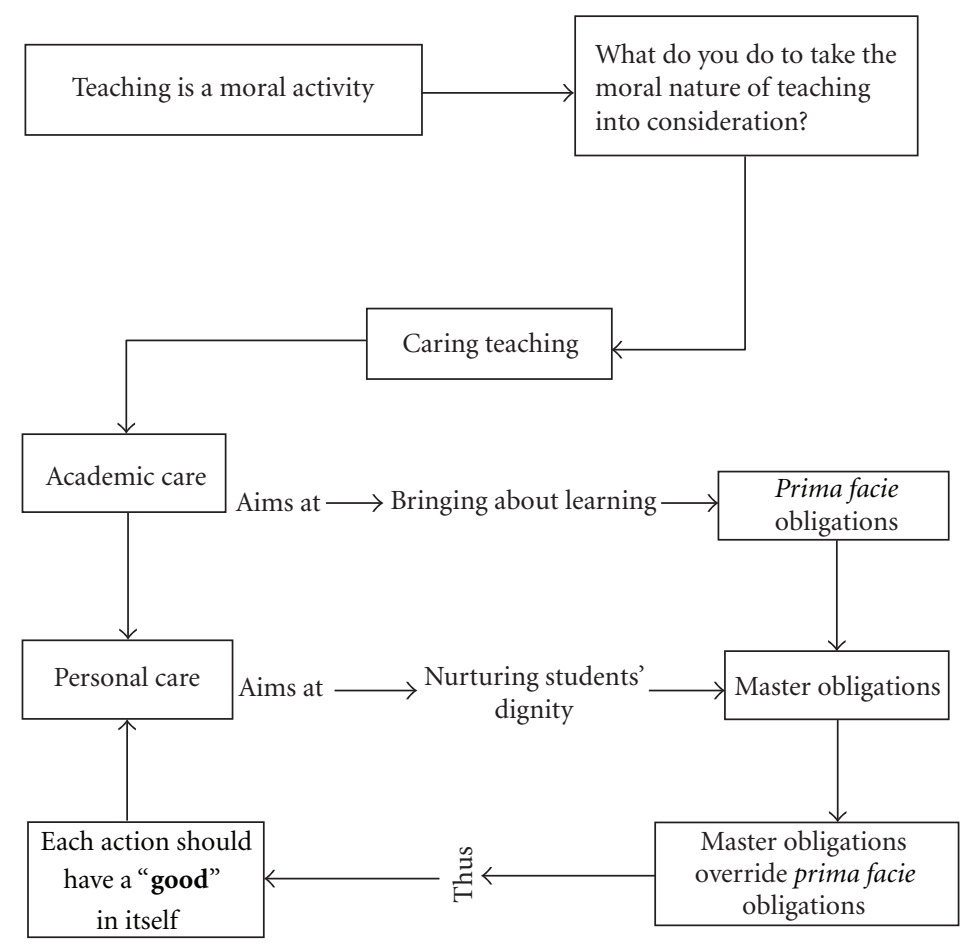

Figure 1: Moral nature of teaching practice.

TABLE 5: Mean differences between personal care and academic care with CTS $(n=556)$.

\begin{tabular}{lccccc}
\hline Dimensions & Mean & SD & Mean D & $t$ & $P$ \\
\hline Personal care & 4.17 & 0.52 & 0.45 & 20.39 & 0.000 \\
Academic care & 3.08 & 0.62 & -0.64 & -24.02 & 0.000 \\
\hline
\end{tabular}

Test value $=3.85$ significance level $(0.01)$.

reliable difference between male and female on the composite dependent caring teaching: $F(2,553)=19.82, P<0.01$, partial $\eta^{2}=0.067$. Both groups perceived personal care (for male: $M=4.13, \mathrm{SD}=0.52$; for female $M=4.22, \mathrm{SD}=.51$ ) as more important than academic care (for male: $M=2.94$, $\mathrm{SD}=0.62$; for female: $M=3.27, \mathrm{SD}=0.58$ ). This data also suggest that in both cases female teachers give caring teaching higher scores than male teachers do. The partial eta square indicates that gender accounts for 0.067 of the total variance of caring teaching.

Regarding the subject matters taught by the teachers, the results of a multivariate test showed no statistically significant differences: $F(4,1104)=1.21, P<0.05$, partial $\eta^{2}=$ 0.04. In personal care, the perceived scores were $M=4.19$, $\mathrm{SD}=0.50$ for humanities and literature teachers, $M=4.15$, $\mathrm{SD}=0.48$ for mathematics and science teachers, and $M=$ $4.15, \mathrm{SD}=0.59$ for primary teachers who taught multiple subjects. Compared with personal care, in academic care, the scores were lower but still no statistically significant differences were found on the basis of the subject matters taught by the teachers: $M=3.08, \mathrm{SD}=0.57$ for humanities and literature teachers; $M=3.16, \mathrm{SD}=0.61$ for mathematics and science; $M=2.99, \mathrm{SD}=0.73$ for primary teachers.

\section{Conclusion and Discussion}

In order to gain some insight into the moral aspect of teaching, this paper aimed at exploring possible dimensions of caring teaching. Drawing on the existing literature and our previous research, we found that the concepts of personal and academic care could help us to explore the possible dimensions of caring teaching $[4,10,15,20]$. The results of exploratory factor analysis showed that the teachers perceived four dimensions with regard to caring teaching, with factor 1: "nurture the character of the students"; factor 2: "didactical bias"; factor 3: "respectful didactics"; factor 4: "awareness," each explaining 25.85, 10.66, 7.44, and 5.84 variance, respectively. The total variance of the model was 52.54. In line with existing literature, we categorized these dimensions into two general dimensions: (1) "personal care" consisted of two subscales, namely, "nurture students' character" and "awareness"; (2) "academic care" included two subscales, namely, "didactical bias" and "respectful didactics." We believe that at the core of personal care and its corresponding dimensions is a concern about nurturing the whole character of students as human beings. The main intention of academic care, however, is to help students enhance their learning properties. For a caring teacher, to place learning at the core of academic care does not mean to use any tool in order to enhance students' learning. Caring teaching in this sense calls for respectful and sensitive didactics to serve the dignity and humanity of the students. 
TABLE 6: The final items included in the caring teaching scale.

\begin{tabular}{|c|c|}
\hline Factors & Items \\
\hline \multirow{7}{*}{ Nurturing the students' character } & (1) It is important for a teacher to care about nonacademic matters of students. \\
\hline & (2) In addition to academics, teachers are expected to care about students' social skills. \\
\hline & (3) Teachers should care about dignity of students. \\
\hline & (4) It is a teacher' duty to care about the personal character of the students. \\
\hline & (5) Teachers should care about moral properties of students. \\
\hline & (6) Teachers should care about students' behaviors in the social contexts out of school. \\
\hline & (7) Teachers should care about emotional properties of students. \\
\hline \multirow{3}{*}{ Didactical bias } & (8) It is fair if teachers give more academic freedom to the gifted students. \\
\hline & (9) It is fair if teachers pay more attention to the active students. \\
\hline & (10) It is fair if teachers engage good students in the learning activities. \\
\hline \multirow{4}{*}{ Awareness } & $\begin{array}{l}\text { (11) Teachers are expected to be aware of students problems which are related to the matters outside } \\
\text { of classroom. }\end{array}$ \\
\hline & (12) It is teachers' responsibility to be aware of students' different capabilities. \\
\hline & (13) Teachers should be aware of students' background. \\
\hline & (14) Teachers are expected to be aware of students' needs and interests. \\
\hline \multirow{7}{*}{ Respectful didactics } & (15) It is effective if teachers punish carless students in the front of classmates. \\
\hline & $\begin{array}{l}\text { (16) As far as teachers' method brings about learning, it does not matter if the method put pressure } \\
\text { on students. }\end{array}$ \\
\hline & (17) Teachers can justify any method to improve learning of poor students. \\
\hline & (18) Teachers' pedagogical activities should only focus on students' academic achievement. \\
\hline & (19) It is an effective rule if teachers ask students leave the classroom to discipline them. \\
\hline & (20) Teachers should be harsh to force students improve their academic learning. \\
\hline & (21) Teachers' methods should be fixed based on typical students' capability. \\
\hline
\end{tabular}

Our results are consistent with the ideas of "manner" and "methods" in teaching proposed by Gary Fenstermacher $[5,13,14,28]$. It also confirms that teaching is a kind of "practice" that has "intrinsic good" as it is elaborated from the perspective of "neo-Aristotelian" [29-32].

Considering both personal and academic care, the results showed that teachers perceived personal care $(M=4.17, \mathrm{SD}=$ $0.52)$ to be more important than academic care $(M=3.08$, $\mathrm{SD}=0.62$ ). As such, drawing on Audi [11], we argue that the moral aspect of teaching calls for two interrelated obligations: master and prima facie obligations. In prima facie obligations, according to Audi, "to each obligation (or duty), there corresponds a principle to the effect that we (morally) should fulfil it. The "should," however, like "duty" as Ross used it, does not designate the presence of a final, that is, overriding, moral obligation." Master obligation can, however, support a final moral obligation in a way no single prima facie can do. On master principle theories, any prima facie principle owes its authority to the master principle [10]. In line with our results, the intentions (e.g., bring about learning) embedded in academic care correspond to prima facie obligations which will be overridden in the presence of a master obligation (e.g., to nurture the dignity of students). Figure 1 illustrates the moral aspects of teaching based on findings from this research.

The last part of our results suggested that there was a statistically significant difference between male teachers and female teachers in terms of perceived personal and academic care. Both groups perceived personal care (for male: $M=$
$4.13, \mathrm{SD}=0.52$; for female $M=4.22, \mathrm{SD}=0.51$ ) as more important than academic care (for male: $M=2.94, \mathrm{SD}=$ 0.62 ; for female: $M=3.27, \mathrm{SD}=0.58)$. However, a multivariate test analysis showed no statistically significant differences among teachers when we studied the subject matters they taught. This result is consistent with other empirical research that found that female teachers valued caring more in the context of teaching [24]. Such a result is also in accordance with the nature of caring teaching, which is considered as "mothering" [15]. In conclusion, we believe that this paper proposes a promising conceptual framework to further qualitative and particularly quantitative reflection on the moral aspect of teaching. In line with this, we suggest that prospective researchers use the Caring Teaching Scale developed in this research in order to improve its psychometric properties in different contexts.

\section{References}

[1] J. Schuitema, G. T. Dam, and W. Veugelers, "Teaching strategies for moral education: a review," Journal of Curriculum Studies, vol. 40, no. 1, pp. 69-89, 2008.

[2] H. Sockett and P. LePage, "The missing language of the classroom," Teaching and Teacher Education, vol. 18, no. 2, pp. 159$171,2002$.

[3] J. Husu and K. Tirri, "Developing whole school pedagogical values - a case of going through the ethos of 'good schooling', Teaching and Teacher Education, vol. 23, no. 4, pp. 390-401, 2007. 
[4] R. V. Bullough, "Ethical and moral matters in teaching and teacher education," Teaching and Teacher Education, vol. 27, no. 1, pp. 21-28, 2011.

[5] C. Fallona, "Manner in teaching: a study in observing and interpreting teachers' moral virtues," Teaching and Teacher Education, vol. 16, no. 7, pp. 681-695, 2000.

[6] D. T. Hansen, "The moral is in the practice," Teaching and Teacher Education, vol. 14, no. 6, pp. 643-655, 1998.

[7] G. Colnerud, "Ethical conflicts in teaching," Teaching and Teacher Education, vol. 13, no. 6, pp. 627-635, 1997.

[8] O. Shapira-Lishchinsky, "Teachers' critical incidents: ethical dilemmas in teaching practice," Teaching and Teacher Education, vol. 27, no. 3, pp. 648-656, 2011.

[9] G. D. Fenstermacher, "Some moral considerations on teaching as a porfession," in The Moral Dimensions of Teaching, J. I. Goodlad, R. Soder, and K. Sirotnik, Eds., pp. 130-154, Jossey Bass, San Francisco, Calif, USA, 1990.

[10] K. Gholami, "Moral care and caring pedagogy: two dimensions of teachers' praxis," Pedagogy, Culture \& Society, vol. 19, no. 1, pp. 133-151, 2011.

[11] R. Audi, Practical Reasoning and Ethical Decisions, Routledge, New York, NY, USA, 2006.

[12] V. Richardson and G. D. Fenstermacher, "Manner in teaching: the study in four parts," Journal of Curriculum Studies, vol. 33, no. 6, pp. 631-637, 2001.

[13] D. T. Hansen, "Reflections on the manner in teaching project," Journal of Curriculum Studies, vol. 33, no. 6, pp. 729-735, 2001.

[14] G. D. Fenstermacher, "On the concept of manner and its visibility in teaching practice," Journal of Curriculum Studies, vol. 33, no. 6, pp. 639-653, 2001.

[15] J. H. James, "Caring for "others": examining the interplay of mothering and deficit discourses in teaching," Teaching and Teacher Education, vol. 28, no. 2, pp. 165-173, 2012.

[16] L. Isenbarger and M. Zembylas, "The emotional labour of caring in teaching," Teaching and Teacher Education, vol. 22, no. 1, pp. 120-134, 2006.

[17] K. Webb and J. Blond, "Teacher knowledge: the relationship between caring and knowing janet blond Claiming an Epistemological Role for Caring Theoretical Frame," Teaching and Teacher Education, vol. 11, no. 6, pp. 611-625, 1995.

[18] L. S. Goldstein and V. E. Lake, "Love, love, and more love for children: exploring preservice teachers' understandings of caring," Teaching and Teacher Education, vol. 16, no. 8, pp. 861-872, 2000.

[19] N. Noddings, Educating Moral People: A Caring Alternative to Character Education, Teacher College Press, New York, NY, USA, 2002.

[20] A. de Guzman, R. K. C. Torres, M. M. Uy, J. B. F. Tancioco, E. Y. Siy, and J. R. Hernandez, "From teaching from the heart to teaching with a heart: segmenting filipino college students "views of their teachers" caring behavior and their orientations as cared-for individuals," Asia Pacific Education Review, vol. 9, no. 4, pp. 487-502, 2008.

[21] F. Vogt, "A caring teacher: explorations into primary school teachers' professional identity and ethic of care," Gender and Education, vol. 14, no. 3, pp. 251-264, 2002.

[22] J. Rosiek, "Emotional scaffolding: an exploration of the teacher knowledge at the intersection of student emotion and the subject matter," Journal of Teacher Education, vol. 54, no. 5, pp. 399-412, 2003.

[23] K. Gholami and J. Husu, "How do teachers reason about their practice? Representing the epistemic nature of teachers' practical knowledge," Teaching and Teacher Education, vol. 26, no. 8, pp. 1520-1529, 2010.
[24] B. Tosolt, "Gender and race differences in middle school students' perceptions of caring teacher behaviors," Multicultural Perspectives, vol. 12, no. 3, pp. 145-151, 2010.

[25] J. Nias, "Primary teaching as a culture of care School culture," in School Culture, J. Prosser, Ed., Paul Chapman, London, UK, 1999.

[26] J. L. Horn, "A rationale and test for the number of factors in factor analysis," Psychometrika, vol. 30, no. 2, pp. 179-185, 1965.

[27] J. C. Hayton, D. G. Allen, and V. Scarpello, "Factor retention decisions in exploratory factor analysis: a tutorial on parallel analysis," Organizational Research Methods, vol. 7, no. 2, pp. 191-205, 2004.

[28] V. Richardson and C. Fallona, "Classroom management as method and manner," Journal of Curriculum Studies, vol. 33, no. 6, pp. 705-728, 2001.

[29] J. Dunne, "Arguing for teaching as a practice: a reply to alasdair macIntyre," Journal of Philosophy of Education, vol. 37, no. 2, pp. 353-369, 2003.

[30] J. Dunne, "An intricate fabric: understanding the rationality of practice," Pedagogy, Culture \& Society, vol. 13, no. 3, pp. 367390, 2005.

[31] D. Carr, "Rival conceptions of practice in education and teaching," Journal of Philosophy of Education, vol. 37, no. 2, pp. 253-266, 2003.

[32] W. Carr, "Philosophy and education," Journal of Philosophy of Education, vol. 38, no. 1, pp. 55-73, 2004. 


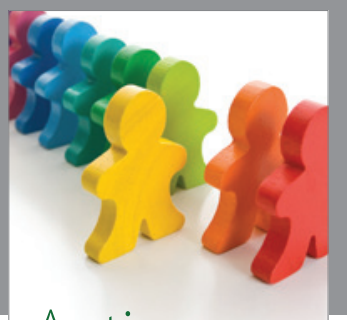

Autism

Research and Treatment
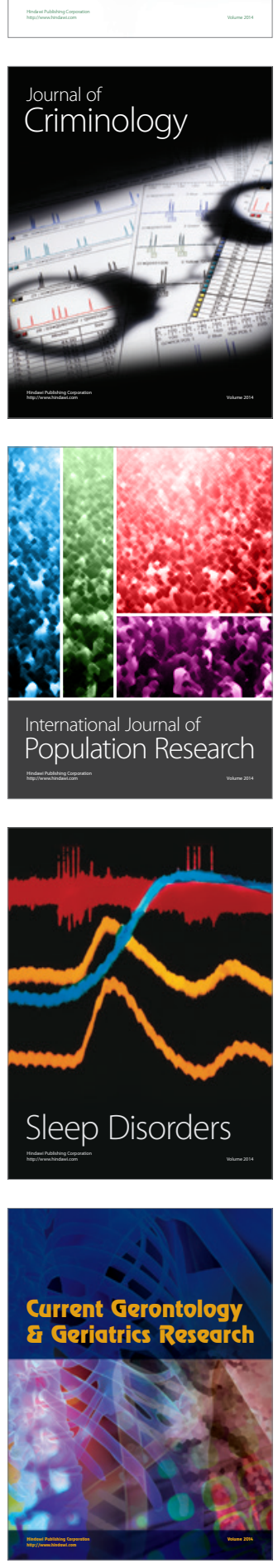
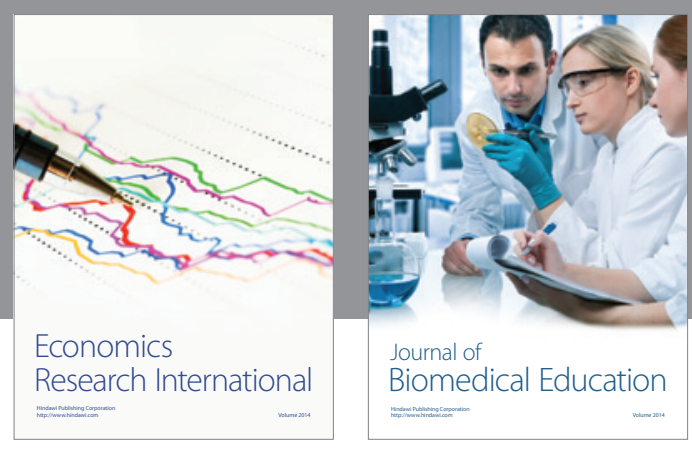

Journal of

Biomedical Education

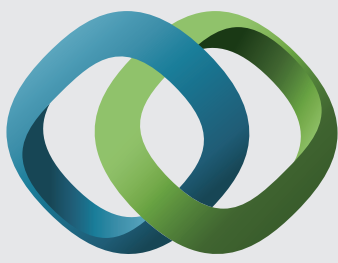

\section{Hindawi}

Submit your manuscripts at

http://www.hindawi.com
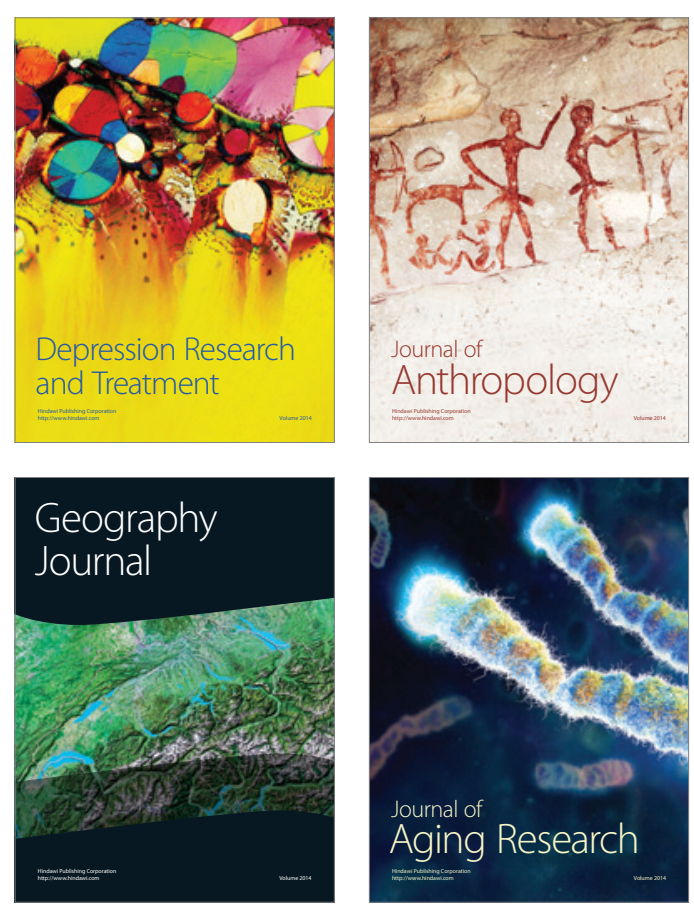

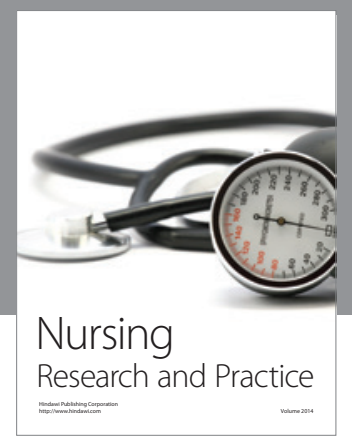

Nursing

Research and Practice

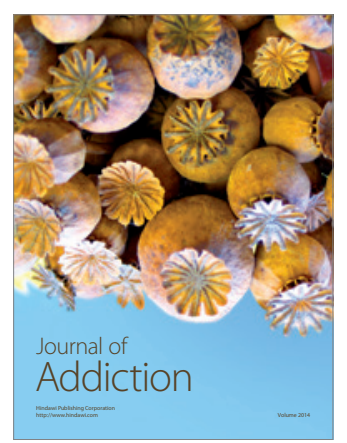

Child Development

Research

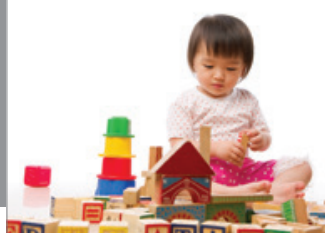

迥
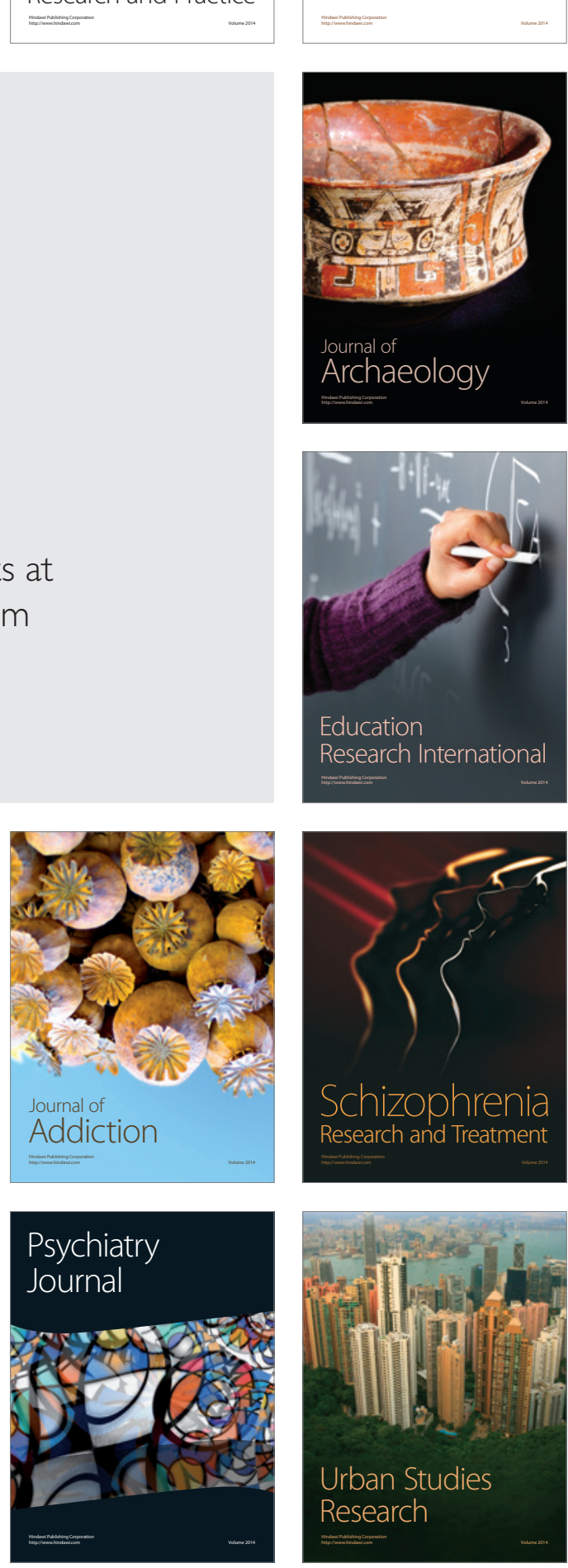